\title{
Editorial on the Current Role of Ultrasound
}

\author{
Christoph F. Dietrich ${ }^{1, *(0)}$, Claude B. Sirlin ${ }^{2}$, Mary O'Boyle ${ }^{3}$, Yi Dong ${ }^{4}$ and Christian Jenssen ${ }^{5}$ \\ 1 Department of Internal Medicine 2, Caritas-Krankenhaus Bad Mergentheim, \\ D-97980 Bad Mergentheim, Germany \\ 2 Liver Imaging Group, Department of Radiology, University of California, San Diego, CA 92093, USA \\ 3 Department of Radiology, University of California, San Diego, CA 92093, USA \\ 4 Department Allgemeine Innere Medizin (DAIM), Kliniken Hirslanden Beau Site, Salem und Permanence, \\ 3013 Bern, Switzerland \\ 5 Department of Internal Medicine, Krankenhaus Märkisch Oderland, Strausberg and Brandenburg Institute \\ for Clinical Ultrasound, Medical University Brandenburg, 16816 Neuruppin, Germany \\ * Correspondence: Christoph.dietrich@ckbm.de; Tel.: +49-(0)7931-58-2201 (ext. 2200); \\ Fax: +49-(0)7931-58-2290
}

Received: 14 July 2019; Accepted: 12 August 2019; Published: 26 August 2019

check for updates

\begin{abstract}
Ultrasound (US) is an important imaging tool and the most commonly used imaging modality worldwide. Although US requires expertise to be performed at the highest quality levels, basic US exams can be learned by most physicians and medical technologists with knowledge of human anatomy and with physical examination skills. The full potential of US is achieved when it is more than a pure "imaging modality", but instead an integrated clinical, physical, and imaging assessment in which the examiner interacts directly and personally with the patient. Specific diagnostic US knowledge is strongly encouraged for specialist training in clinical disciplines.
\end{abstract}

Keywords: ultrasound; education; point-of-care ultrasound; medical students; training

\section{Introduction}

Ultrasound (US) is an important imaging tool and the most commonly used imaging modality worldwide. Lack of ionizing radiation, low cost, high portability and its non-invasive nature has made ultrasound a very attractive tool for clinical diagnosis. More money is spent on ultrasound examinations compared to computed tomography (CT) and magnetic resonance imaging (MRI) [1,2].

According to the World Health Organisation (WHO), about two thirds of the world population have no access to any kind of imaging $[3,4]$. Due to its portability and relatively lower purchasing and maintenance costs, US as a front-line modality is a critical element in any strategic approach for solving this enormous global problem. By comparison, in most parts of the world, CT and MRI will be more appropriate as second- or third-line modalities due to their higher costs and lack of portability.

Although US requires expertise to be performed at the highest levels of quality, basic US exams can be learned by most physicians and medical technologists with knowledge of human anatomy and with physical examination skills. Typically, there are three levels of ultrasound equipment utilized in student education, from the hand-held devices, point-of-care-ultrasound cart-based systems, to larger and more expensive high-resolution ultrasound systems with advanced capabilities. Standardized educational material to facilitate training is freely available (e.g., EFSUMB-website) [5,6].

The full potential of US is achieved when it is more than a pure "imaging modality" but instead is an integrated clinical, physical, and imaging assessment in which the examiner interacts directly and personally with the patient 


\section{The Advantages of Ultrasound}

There are several advantages of ultrasound as an imaging modality: It has higher spatial resolution than CT and MRI, exquisite anatomical definition for superficial and many deeper structures, real time imaging capabilities, wide availability, and a broad range of clinical applications including surveillance, diagnosis, disease monitoring, and guidance of interventions [7,8]. Additionally, US delivers no ionizing radiation and is significantly less expensive, with lower purchasing and maintenance costs than comparable imaging modalities such as MRI and CT [9].

US can be applied in a traditional fashion, for examination of the abdomen by gastroenterologists and surgeons [10-14], the pelvis by gynaecologists [15,16], the heart by cardiologists [17], the mediastinum and lung by pneumologists, and other anatomical regions examined by their respective specialists. The role of radiology depends on historical issues and traditions [18-21]. The performance of ultrasound by clinicians can be a rewarding and satisfying part of their practice, enabling the rapid delivery of a powerful diagnostic and therapeutic tool. There is no absolute need to delegate ultrasound scanning to nonphysicians, except in certain practice settings such as North America, where routine performance of US by physicians introduces logistical challenges and raises costs [20]. In such settings, it is usually necessary for routine exams to be performed by highly trained non-physician personnel (so called sonographers) under the supervision of radiologists or other physicians, while reserving physician scanning for complex exams or exams with unusual findings.

In addition, US might be also applied as a problem solving tool (point-of-care US) in a defined clinical setting, for example, in the prehospital setting, emergency room and intensive care unit [8].

The traditional way of performing US examinations can be termed comprehensive or conventional ultrasound. In contrast to conventional ultrasound, the use of mobile and portable US scanners allows examiners immediate access to clinical imaging for rapid and direct solutions. WFUMB (World Federation for Ultrasound in Medicine and Biology) has published a position paper which discusses the current status and future perspectives of point-of-care US [8]. According to this organization, point-of-care US is defined as "ultrasound performed bedside and interpreted directly by the treating clinician or other specialist" [8]. The authors of this editorial have added the qualifier "or other specialists" in recognition that in some settings (battlefield, ambulance, remote rural clinics, etc.) it may not be practical to mandate clinician-performed portable US. In some settings, other personnel (e.g., trained soldiers, paramedics, physician assistants) may need to perform the scanning.

A recent article by Karl-Heinz Seitz [21] makes a strong argument for physician-performed US. "The main message of the groundbreaking publication by G. Rettenmaier in 1976 was that fast B-mode ultrasound represents an expansion of physical examination by technical means termed as "clinical ultrasound" [22,23] and as a "dialog-based examination method" [24]. The probe acts as the palpating hand while the physician communicates verbally with the patient. This allows the clinician to record a more in-depth case history and also allows for a more precise determination of the problem. The critical synthesis of imaging and symptoms allows definitive diagnoses that would not be possible without US, clinical knowledge, and consultation with a physician" [21]. While we agree in principle with the main concepts articulated by Seitz, we recognize that highly trained nonphysician personnel can also perform many of the dialogue and communication tasks. There have been no prospective studies showing that physician-performed US provides higher accuracy, improves patient outcomes, or is preferred by patients compared to sonographer-performed US.

\section{US in Guidelines}

US has been included in many but not all clinical practice guidelines as a first-line imaging tool or extended physical examination [25]. For example, while the guidelines of the European Association for Study of the Liver (EASL) recommend contrast enhanced ultrasound [26] for the workup and management of incidentally detected focal liver lesions, the guidelines of the American College of Gastroenterology (ACG) neglect US entirely [27]. The role of specific ultrasound techniques—contrast enhanced ultrasound [28-31], elastography [13,32-34], interventional ultrasound [35-44]-has been 
discussed in prior EFSUMB and WFUMB [45-48] guidelines. There is a need for more uniform incorporation of US in international clinical practice guidelines for appropriate and evidence-based indications. To this end, participation of clinicians and radiologists with expertise in US in guideline committees should be encouraged and facilitated by ultrasound societies $[49,50]$.

Statement 1: Ultrasound should be included in clinical practice guidelines as supported by published evidence and clinical value.

Statement 2: Ultrasound societies should advocate for adequate representation of clinicians and radiologists with expertise in ultrasound in guidelines committees.

\section{Who Should Perform US}

Worldwide, US is performed by general practitioners, medical specialists and subspecialists, radiologists and in some countries also by non-medical sonographers with formal ultrasound training. Below we discuss both physician-performed and sonographer-performed US.

US can be performed by physicians, including general practitioners, medical specialists and subspecialists, as an extended physical examination as part of their practice. In this setting, services of a radiologist or sonographer are not routinely required [20,21,51,52]. This form of US is applied in many European countries including Germany, Italy, Romania and others. Many medical specialities include US in their teaching curriculum, and specialists perform specific US exams relevant to their areas of expertise. Thus, echocardiography is performed mainly by cardiologists, hepatic and endoscopic ultrasound by gastroenterologists, obstetrical US by obstetricians, and endobronchial ultrasound by pneumologists.

The radiological delivery of service by physicians and sometimes by sonographers is traditionally offered in English-speaking countries around the world, notably the United States, Canada and Australia. In such scenarios US is performed and reported as a radiological procedure similar to CT or MRI. In this radiological setting, the examination can be performed by physicians or sonographers. The latter are highly specialized imaging technologists with rigorous formal training and regulatory certification in ultrasound who typically work within a radiology department under the supervision of one or more radiologists $[20,51]$. Despite their extensive training and high procedural skill, sonographers function as "delegated agents of the physician and do not practice independently" [53,54], according to the Society of Diagnostic Medical Sonography. Thus, although scanning is done by sonographers, images are evaluated and results reported by radiologists [21,55]. Historically, radiologists reviewed static images selected by the sonographer as being representative of the entire exam, but it is becoming increasingly common for sonographers to capture cinematic sweeps in different planes through the organ(s) and lesion(s) of interest so that the interpreting radiologist can benefit from the wealth of information gained from the real-time study [20,21,51,52].

In the UK, by comparison, sonographers are independent reporting practitioners in the National Health Service (NHS) [20,51,52]. In the NHS, most (about $80 \%$ ) US services are performed and reported independently by sonographers. The few remaining US examinations are performed by radiologists $(19 \%)$ and other medically trained practitioners $(<1 \%)[20,21,51,52]$. The role of US in the UK is controversial, since non-medical sonographers intrinsically have less medical education, general knowledge and independence than medical doctors [20,21,51,52]. The non-medical sonographer is unlikely to achieve a truly independent status independent of healthcare costs [20,51,52]. In other regions of the world, the sonographer is a non-radiologist physician specialized in ultrasound, as is in parts of China [56]. Ideally, to maximize patient care and safety, US practice should be undertaken by educated, qualified and healthcare system regulated personnel. Professional US care should include point-of-care US and specialized primary, secondary and tertiary care level defined qualifications achieved by specialists and subspecialists including radiology.

Statement 3: Ultrasound should be performed by physicians in their respective speciality and/or by highly trained, certified medical sonographers.

Statement 4: Ultrasound is traditionally part of radiology in Anglo-American countries. 
Statement 6: The role of non-medical sonographers is controversial. Research is needed to compare the quality and safety of US performed by non-medical sonographers compared to certified medical sonographers and physician specialists.

Statement 7: The ultrasound findings should be reported by a physician able to integrate the imaging findings and clinical data.

\section{The Radiology Point of View}

As discussed above, there are many advantages of physician-performed ultrasound. Nevertheless, there are also compelling advantages for ultrasound scanning by highly trained sonographers under the supervision of radiologists and working within a radiology department.

First, this approach enhances efficiency, flexibility, and coverage. A single radiologist can reasonably and accurately report over 100 ultrasound exams a day when the scanning is performed by a team of experienced sonographers. It would not be possible for a clinician to scan nearly as many patients. Additionally, since all sonographers on the team are skilled in performing a broad array of exams involving different organ systems, exams can be scheduled flexibly based on urgency and patient convenience; except for rare highly specialized exams requiring particular expertise, the type of exam is not relevant since a number of sonographers have the necessary technical ability. Moreover, since US is often a front-line modality, the frequency of normal exams is high. In the authors' experience, most US exams are negative or reveal only relatively simple abnormalities (e.g., renal cysts, gallstones, small fibroids, etc.); the benefits of a physician performing all exams, including those with routine findings, have not been proved. Rather than systematically scanning all patients, radiologists scan only those patients in which their direct involvement is necessitated by confusing findings, complex anatomy, or complicated history. Finally, by centralizing US scanning within a radiology department, it is possible to ensure that all US procedures are offered to patients consistently and throughout the year, without having to schedule around particular physicians' availability.

Second, this approach enables standardization and rigorous quality assurance, since all exams are performed using standard institutional protocols and reviewed by radiologists, which provides a mechanism for feedback to the sonographers. Additionally, one of the more experienced sonographers can serve as personnel supervisor and, in this capacity, organize and lead regular quality improvement projects requiring the participation of all sonographers in the department. Finally, it should be emphasized that sonographers accrue extremely high levels of sonographic skill, experience, and expertise. By performing many hours of scanning every day for many years, they achieve a mastery of their art that would be hard to match by a busy physician that performs many complex tasks in addition to sonography.

Third, this approach facilitates the purchase and maintenance of the highest quality, state-of-the-art scanners. Since departments often purchase multiple scanners, they can negotiate competitive prices from scanner manufacturers, which allows them to purchase top-end scanners at relatively low costs. Additionally, departments may have greater access to physics and technical support, either internally from their own personnel or externally from the manufacturers, which allows the scanners to be maintained at the highest performance levels.

\section{Who Should Learn Ultrasound}

Optimal use of US devices needs dedicated education and practical training. A key goal is to make US available to every patient who needs this service. This will improve diagnostic efficiency and possibly the management of patients [8,57].

US training across the world is variable and dependent on many factors. In regions where US is performed predominantly by physicians, it is important that US be taught from the beginning of medical education, that is, in medical schools and universities $[58,59]$. The practical lectures could begin during anatomy courses. WFUMB is currently reporting on the use of US student medical education and the papers will be published soon. After learning basic concepts and skills, physicians 
in training should refine their US examination skills by adhering to curricula such as those proposed by EFSUMB $[5,6,60]$ and WFUMB $[10,11]$. As physicians specialize in certain areas, for example, cardiology, gastroenterology and obstetrics, they can hone their procedural and interpretive skills by focusing on ultrasound exams in the areas of their clinical expertise. This way, they can leverage their subspecialty knowledge of clinical, sonographic and pathological findings to render an accurate diagnosis and make optimal management recommendations.

All radiologists should learn US, even those who practice in regions such as the United States, in which sonography is performed routinely by sonographers. The reasons for this are that knowledge of US scanning enhances the radiologist's image interpretation capabilities, allows the radiologist to interact effectively with the sonographer, and enables the radiologist to scan patients with a particularly difficult or confusing anatomy or findings. For this reason, radiology residency programs require US scanning as part of their curriculum. They also require several dedicated rotations on the US service, commensurate to rotations in CT and MRI. Finally, in regions in which US is performed by sonographers, US should be learned by imaging technologists who have the ability and willingness to undergo intense formal training in US.

Statement 8: Ultrasound should be part of the teaching curriculum of all medical specialities in which US is relevant.

Statement 9: Sonographers should have prior training as medical imaging, before they undergo an additional postgraduate training in US.

Statement 10: For radiologists, US training should be commensurate to training in CT and MRI.

\section{Conclusions}

The full potential of US is achieved when it is more than a pure "imaging modality", but is instead an integrated clinical, physical, and imaging assessment in which the examiner interacts directly and personally with the patient. Specific diagnostic US knowledge is strongly encouraged for specialist training in clinical disciplines. US education should be incorporated into all medical specializations, which is also true for contrast enhanced US $[28,29,61]$ and other specific techniques. For aspiring physicians, US medical education should start in medical school. Point-of-care US is widely accepted as a practical way to monitor the progress of a pregnant patient from five weeks gestation to term. In fetal imaging, obstetricians have established global standards for diagnosis, training, and quality control (DEGUM 3-level model); similar models should be achieved by other specialities $[8,55]$.

Author Contributions: All authors equally contributed to this paper with conception and design of the study, literature review and analysis, drafting and critical revision and editing, and final approval of the final version.

Acknowledgments: The authors thank the Bad Mergentheimer Leberzentrum e.V. for support.

Conflicts of Interest: No potential conflicts of interest. No financial support.

\section{References}

1. Smajerova, M.; Petrasova, H.; Little, J.; Ovesna, P.; Andrasina, T.; Valek, V.; Nemcova, E.; Miklosova, B. Contrast-enhanced ultrasonography in the evaluation of incidental focal liver lesions: A cost-effectiveness analysis. World J. Gastroenterol. 2016, 22, 8605-8614. [CrossRef] [PubMed]

2. Westwood, M.; Joore, M.; Grutters, J.; Redekop, K.; Armstrong, N.; Lee, K.; Gloy, V.; Raatz, H.; Misso, K.; Severens, J.; et al. Contrast-enhanced ultrasound using SonoVue(R) (sulphur hexafluoride microbubbles) compared with contrast-enhanced computed tomography and contrast-enhanced magnetic resonance imaging for the characterisation of focal liver lesions and detection of liver metastases: A systematic review and cost-effectiveness analysis. Health Technol. Assess. 2013, 17, 1-243. [CrossRef] [PubMed]

3. Belard, S.; Tamarozzi, F.; Bustinduy, A.L.; Wallrauch, C.; Grobusch, M.P.; Kuhn, W.; Brunetti, E.; Joekes, E.; Heller, T. Point-of-Care Ultrasound Assessment of Tropical Infectious Diseases-A Review of Applications and Perspectives. Am. J. Trop. Med. Hyg. 2016, 94, 8-21. [CrossRef] [PubMed] 
4. Anderson, B.O.; Braun, S.; Carlson, R.W.; Gralow, J.R.; Lagios, M.D.; Lehman, C.; Schwartsmann, G.; Vargas, H.I. Overview of breast health care guidelines for countries with limited resources. Breast J. 2003, 9 (Suppl. S2), S42-S50. [CrossRef]

5. Dietrich, C.F.; Rudd, L.; Saftiou, A.; Gilja, O.H. The EFSUMB website, a great source for ultrasound information and education. Med. Ultrason. 2017, 19, 102-110. [CrossRef] [PubMed]

6. Dietrich, C.F.; Rudd, L. The EFSUMB website, a guide for better understanding. Med. Ultrason. 2013, 15, 215-223. [CrossRef] [PubMed]

7. Allan, A.; Bedforth, N.; Nicholls, B.; Denny, N. Comparing ultrasound and nerve stimulation: Time to ask the question? Anaesthesia 2011, 66, 222-223. [CrossRef]

8. Dietrich, C.F.; Goudie, A.; Chiorean, L.; Cui, X.W.; Gilja, O.H.; Dong, Y.; Abramowicz, J.S.; Vinayak, S.; Westerway, S.C.; Nolsoe, C.P.; et al. Point of Care Ultrasound: A WFUMB Position Paper. Ultrasound Med. Biol. 2017, 43, 49-58. [CrossRef]

9. Nazarian, L.N. Sound judgment. J. Ultrasound Med. 2012, 31, 187. [CrossRef]

10. Atkinson, N.S.S.; Bryant, R.V.; Dong, Y.; Maaser, C.; Kucharzik, T.; Maconi, G.; Asthana, A.K.; Blaivas, M.; Goudie, A.; Gilja, O.H.; et al. How to perform gastrointestinal ultrasound: Anatomy and normal findings. World J. Gastroenterol. 2017, 23, 6931-6941. [CrossRef]

11. Atkinson, N.S.; Bryant, R.V.; Dong, Y.; Maaser, C.; Kucharzik, T.; Maconi, G.; Asthana, A.K.; Blaivas, M.; Goudie, A.; Gilja, O.H.; et al. WFUMB Position Paper. Learning Gastrointestinal Ultrasound: Theory and Practice. Ultrasound Med. Biol. 2016, 42, 2732-2742. [CrossRef] [PubMed]

12. Maconi, G.; Nylund, K.; Ripolles, T.; Calabrese, E.; Dirks, K.; Dietrich, C.F.; Hollerweger, A.; Sporea, I.; Saftoiu, A.; Maaser, C.; et al. EFSUMB Recommendations and Clinical Guidelines for Intestinal Ultrasound (GIUS) in Inflammatory Bowel Diseases. Ultraschall Med. 2018, 39, 304-317. [CrossRef] [PubMed]

13. Nylund, K.; Maconi, G.; Hollerweger, A.; Ripolles, T.; Pallotta, N.; Higginson, A.; Serra, C.; Dietrich, C.F.; Sporea, I.; Saftoiu, A.; et al. EFSUMB Recommendations and Guidelines for Gastrointestinal Ultrasound. Ultraschall Med. 2017, 38, 273-284. [CrossRef] [PubMed]

14. Nylund, K.; Maconi, G.; Hollerweger, A.; Ripolles, T.; Pallotta, N.; Higginson, A.; Serra, C.; Dietrich, C.F.; Sporea, I.; Saftoiu, A.; et al. EFSUMB Recommendations and Guidelines for Gastrointestinal Ultrasound. Ultraschall Med. 2017, 38, e1-e15. [CrossRef] [PubMed]

15. Verrotti, C.; Benassi, G.; Caforio, E.; Nardelli, G.B. Targeted and tailored diagnostic strategies in women with perimenopausal bleeding: Advantages of the sonohysterographic approach. Acta Bio Med. Atenei Parm. 2008, 79, 133-136.

16. Menakaya, U.; Reid, S.; Lu, C.; Gerges, B.; Infante, F.; Condous, G. Performance of ultrasound-based endometriosis staging system (UBESS) for predicting level of complexity of laparoscopic surgery for endometriosis. Ultrasound Obstet. Gynecol. Off. J. Int. Soc. Ultrasound Obstet. Gynecol. 2016, 48, 786-795. [CrossRef] [PubMed]

17. Lancellotti, P.; Plonska-Gosciniak, E.; Garbi, M.; Bucciarelli-ducci, C.; Cosyns, B.; Cardim, N.; Galderisi, M.; Edvardsen, T.; Neglia, D.; Plein, S.; et al. Cardiovascular imaging practice in Europe: A report from the European Association of Cardiovascular Imaging. Eur. Heart J. Cardiovasc. Imaging 2015, 16, 697-702. [CrossRef]

18. Monti, J. Revolution or Evolution? A Proposal for the Integration of Point-of-Care Ultrasound Into Physician Assistant Clinical Practice. J. Physician Assist. Educ. 2017, 28, 27-32. [CrossRef]

19. Gibbs, V. A proposed new clinical assessment framework for diagnostic medical ultrasound students. Ultrasound 2014, 22, 113-117. [CrossRef]

20. Edwards, H.M.; Sidhu, P.S. Who's doing your scan? A European perspective on ultrasound services. Ultraschall Med. 2017, 38, 479-482. [CrossRef]

21. Seitz, K. Ultrasound First. Dtsch. Arztebl. Int. 2018, 115, 8-9. [CrossRef] [PubMed]

22. Rettenmaier, G. Sonographic findings depending on the type of diagnostic instruments used. Internist 1982, 23, 565-574. [PubMed]

23. Rettenmaier, G. Sonographic status of upper abdomen. Diagnostic significance and indications of the ultrasonic sectional examination of the upper abdomen. Internist 1976, 17, 549-564. [PubMed]

24. Maio, G. Medicine and the holistic understanding of the human being: Ultrasound examination as dialog. Ultraschall Med. 2014, 35, 98-107. [CrossRef] [PubMed]

25. Elta, G.H.; Enestvedt, B.K.; Sauer, B.G.; Lennon, A.M. ACG Clinical Guideline: Diagnosis and Management of Pancreatic Cysts. Am. J. Gastroenterol. 2018, 113, 464-479. [CrossRef] 
26. European Association for the Study of the Liver. EASL Clinical Practice Guidelines on the management of benign liver tumours. J. Hepatol. 2016, 65, 386-398. [CrossRef] [PubMed]

27. Marrero, J.A.; Ahn, J.; Reddy, K.R. ACG clinical guideline: The diagnosis and management of focal liver lesions. Am. J. Gastroenterol. 2014, 109, 1328-1347. [CrossRef]

28. Claudon, M.; Dietrich, C.F.; Choi, B.I.; Cosgrove, D.O.; Kudo, M.; Nolsoe, C.P.; Piscaglia, F.; Wilson, S.R.; Barr, R.G.; Chammas, M.C.; et al. Guidelines and good clinical practice recommendations for contrast enhanced ultrasound (CEUS) in the liver-update 2012: A wfumb-efsumb initiative in cooperation with representatives of AFSUMB, AIUM, ASUM, FLAUS and ICUS. Ultraschall Med. 2013, 34, 11-29. [CrossRef]

29. Claudon, M.; Dietrich, C.F.; Choi, B.I.; Cosgrove, D.O.; Kudo, M.; Nolsoe, C.P.; Piscaglia, F.; Wilson, S.R.; Barr, R.G.; Chammas, M.C.; et al. Guidelines and good clinical practice recommendations for Contrast Enhanced Ultrasound (CEUS) in the liver-Update 2012: A wfumb-efsumb initiative in cooperation with representatives of AFSUMB, AIUM, ASUM, FLAUS and ICUS. Ultrasound Med. Biol. 2013, 39, 187-210. [CrossRef]

30. Sidhu, P.S.; Cantisani, V.; Dietrich, C.F.; Gilja, O.H.; Saftoiu, A.; Bartels, E.; Bertolotto, M.; Calliada, F.; Clevert, D.A.; Cosgrove, D.; et al. The EFSUMB Guidelines and Recommendations for the Clinical Practice of Contrast-Enhanced Ultrasound (CEUS) in Non-Hepatic Applications: Update 2017 (Short Version). Ultraschall Med. 2018, 39, 154-180. [CrossRef]

31. Sidhu, P.S.; Cantisani, V.; Dietrich, C.F.; Gilja, O.H.; Saftoiu, A.; Bartels, E.; Bertolotto, M.; Calliada, F.; Clevert, D.A.; Cosgrove, D.; et al. The EFSUMB Guidelines and Recommendations for the Clinical Practice of Contrast-Enhanced Ultrasound (CEUS) in Non-Hepatic Applications: Update 2017 (Long Version). Ultraschall Med. 2018, 39, e2-e44. [CrossRef] [PubMed]

32. Dietrich, C.F.; Bamber, J.; Berzigotti, A.; Bota, S.; Cantisani, V.; Castera, L.; Cosgrove, D.; Ferraioli, G.; Friedrich-Rust, M.; Gilja, O.H.; et al. EFSUMB Guidelines and Recommendations on the Clinical Use of Liver Ultrasound Elastography, Update 2017 (Short Version). Ultraschall Med. 2017, 38, 377-394. [CrossRef] [PubMed]

33. Bamber, J.; Cosgrove, D.; Dietrich, C.F.; Fromageau, J.; Bojunga, J.; Calliada, F.; Cantisani, V.; Correas, J.M.; D'Onofrio, M.; Drakonaki, E.E.; et al. EFSUMB guidelines and recommendations on the clinical use of ultrasound elastography. Part 1: Basic principles and technology. Ultraschall Med. 2013, 34, 169-184. [CrossRef] [PubMed]

34. Cosgrove, D.; Piscaglia, F.; Bamber, J.; Bojunga, J.; Correas, J.M.; Gilja, O.H.; Klauser, A.S.; Sporea, I.; Calliada, F.; Cantisani, V.; et al. EFSUMB guidelines and recommendations on the clinical use of ultrasound elastography. Part 2: Clinical applications. Ultraschall Med. 2013, 34, 238-253. [CrossRef] [PubMed]

35. Lorentzen, T.; Nolsoe, C.P.; Ewertsen, C.; Nielsen, M.B.; Leen, E.; Havre, R.F.; Gritzmann, N.; Brkljacic, B.; Nurnberg, D.; Kabaalioglu, A.; et al. EFSUMB Guidelines on Interventional Ultrasound (INVUS), Part I. General Aspects (Short Version). Ultraschall Med. 2015, 36, 464-472. [CrossRef] [PubMed]

36. Sidhu, P.S.; Brabrand, K.; Cantisani, V.; Correas, J.M.; Cui, X.W.; D’Onofrio, M.; Essig, M.; Freeman, S.; Gilja, O.H.; Gritzmann, N.; et al. EFSUMB Guidelines on Interventional Ultrasound (INVUS), Part II. Diagnostic Ultrasound-Guided Interventional Procedures (Long Version). Ultraschall Med. 2015, 36, E15-E35. [CrossRef] [PubMed]

37. Sidhu, P.S.; Brabrand, K.; Cantisani, V.; Correas, J.M.; Cui, X.W.; D’Onofrio, M.; Essig, M.; Freeman, S.; Gilja, O.H.; Gritzmann, N.; et al. EFSUMB Guidelines on Interventional Ultrasound (INVUS), Part II. Diagnostic Ultrasound-Guided Interventional Procedures (Short Version). Ultraschall Med. 2015, 36, 566-580. [CrossRef] [PubMed]

38. Dietrich, C.F.; Lorentzen, T.; Appelbaum, L.; Buscarini, E.; Cantisani, V.; Correas, J.M.; Cui, X.W.; D’Onofrio, M.; Gilja, O.H.; Hocke, M.; et al. EFSUMB Guidelines on Interventional Ultrasound (INVUS), Part III—Abdominal Treatment Procedures (Long Version). Ultraschall Med. 2016, 37, E1-E32. [CrossRef]

39. Dietrich, C.F.; Lorentzen, T.; Appelbaum, L.; Buscarini, E.; Cantisani, V.; Correas, J.M.; Cui, X.W.; D’Onofrio, M.; Gilja, O.H.; Hocke, M.; et al. EFSUMB Guidelines on Interventional Ultrasound (INVUS), Part III—Abdominal Treatment Procedures (Short Version). Ultraschall Med. 2016, 37, 27-45. [CrossRef]

40. Jenssen, C.; Hocke, M.; Fusaroli, P.; Gilja, O.H.; Buscarini, E.; Havre, R.F.; Ignee, A.; Saftoiu, A.; Vilmann, P.; Burmester, E.; et al. EFSUMB Guidelines on Interventional Ultrasound (INVUS), Part IV-EUS-guided Interventions: General aspects and EUS-guided sampling (Long Version). Ultraschall Med. 2016, 37, E33-E76. [CrossRef] 
41. Jenssen, C.; Hocke, M.; Fusaroli, P.; Gilja, O.H.; Buscarini, E.; Havre, R.F.; Ignee, A.; Saftoiu, A.; Vilmann, P.; Burmester, E.; et al. EFSUMB Guidelines on Interventional Ultrasound (INVUS), Part IV_EUS-guided interventions: General Aspects and EUS-guided Sampling (Short Version). Ultraschall Med. 2016, 37, 157-169. [CrossRef]

42. Fusaroli, P.; Jenssen, C.; Hocke, M.; Burmester, E.; Buscarini, E.; Havre, R.F.; Ignee, A.; Saftoiu, A.; Vilmann, P.; Nolsoe, C.P.; et al. EFSUMB Guidelines on Interventional Ultrasound (INVUS), Part V. Ultraschall Med. 2016, 37, 77-99. [CrossRef]

43. Fusaroli, P.; Jenssen, C.; Hocke, M.; Burmester, E.; Buscarini, E.; Havre, R.F.; Ignee, A.; Saftoiu, A.; Vilmann, P.; Nolsoe, C.P.; et al. EFSUMB Guidelines on Interventional Ultrasound (INVUS), Part V-EUS-Guided Therapeutic Interventions (short version). Ultraschall Med. 2016, 37, 412-420. [CrossRef]

44. Jenssen, C.; Brkljacic, B.; Hocke, M.; Ignee, A.; Piscaglia, F.; Radzina, M.; Sidhu, P.S.; Dietrich, C.F. EFSUMB Guidelines on Interventional Ultrasound (INVUS), Part VI-Ultrasound-Guided Vascular Interventions. Ultraschall Med. 2016, 37, 473-476. [CrossRef]

45. Barr, R.G.; Nakashima, K.; Amy, D.; Cosgrove, D.; Farrokh, A.; Schafer, F.; Bamber, J.C.; Castera, L.; Choi, B.I.; Chou, Y.H.; et al. WFUMB guidelines and recommendations for clinical use of ultrasound elastography: Part 2: Breast. Ultrasound Med. Biol. 2015, 41, 1148-1160. [CrossRef]

46. Ferraioli, G.; Filice, C.; Castera, L.; Choi, B.I.; Sporea, I.; Wilson, S.R.; Cosgrove, D.; Dietrich, C.F.; Amy, D.; Bamber, J.C.; et al. WFUMB guidelines and recommendations for clinical use of ultrasound elastography: Part 3: Liver. Ultrasound Med. Biol. 2015, 41, 1161-1179. [CrossRef]

47. Cosgrove, D.; Barr, R.; Bojunga, J.; Cantisani, V.; Chammas, M.C.; Dighe, M.; Vinayak, S.; Xu, J.M.; Dietrich, C.F. WFUMB Guidelines and Recommendations on the Clinical Use of Ultrasound Elastography: Part 4. Thyroid. Ultrasound Med. Biol. 2017, 43, 4-26. [CrossRef]

48. Barr, R.G.; Cosgrove, D.; Brock, M.; Cantisani, V.; Correas, J.M.; Postema, A.W.; Salomon, G.; Tsutsumi, M.; Xu, H.X.; Dietrich, C.F. WFUMB Guidelines and Recommendations on the Clinical Use of Ultrasound Elastography: Part 5. Prostate. Ultrasound Med. Biol. 2017, 43, 27-48. [CrossRef]

49. Dietrich, C.F.; Riemer-Hommel, P. Challenges for the German Health Care System. Z. Gastroenterol. 2012, 50, 557-572. [CrossRef]

50. Dietrich, C.F. Editorial on the contribution "Challenges for the German Health Care System. Z. Gastroenterol. 2012, 50, 555-556. [CrossRef]

51. Edwards, H.; Sidhu, P.S. Who's doing your scan? A reply to Dr Seitz. Ultraschall Med. 2018, 39, e1. [CrossRef]

52. Edwards, H.; Sidhu, P.S. Reply to Dr Seitz. Ultraschall Med. 2018, 39, 94. [CrossRef]

53. Ehler, D.; Carney, D.K.; Dempsey, A.L.; Rigling, R.; Kraft, C.; Witt, S.A.; Kimball, T.R.; Sisk, E.J.; Geiser, E.A.; Gresser, C.D.; et al. Guidelines for cardiac sonographer education: Recommendations of the American Society of Echocardiography Sonographer Training and Education Committee. J. Am. Soc. Echocardiogr. Off. Publ. Am. Soc. Echocardiogr. 2001, 14,77-84. [CrossRef]

54. Edmonds, H.L., Jr.; Isley, M.R.; Sloan, T.B.; Alexandrov, A.V.; Razumovsky, A.Y. American Society of Neurophysiologic Monitoring and American Society of Neuroimaging joint guidelines for transcranial doppler ultrasonic monitoring. J. Neuroimaging Off. J. Am. Soc. Neuroimaging 2011, 21, 177-183. [CrossRef]

55. Anonymous. Statement from the DEGUM board regarding the editorial entitled "Who's Doing Your Scan? A European Perspective on Ultrasound Services.". Ultraschall Med. 2018, 39, 11-13. [CrossRef]

56. Yin, M.G.; Wang, X.T.; Liu, D.W.; Chao, Y.G.; Guan, X.D.; Kang, Y.; Yan, J.; Ma, X.C.; Tang, Y.Q.; Hu, Z.J.; et al. Technical specification for clinical application of critical ultrasonography. Zhonghua Nei Ke Za Zhi 2018, 57, 397-417. [CrossRef]

57. Royse, C.F.; Canty, D.J.; Faris, J.; Haji, D.L.; Veltman, M.; Royse, A. Core review: Physician-performed ultrasound: The time has come for routine use in acute care medicine. Anesth. Analg. 2012, 115, 1007-1028. [CrossRef]

58. Cantisani, V.; Dietrich, C.F.; Badea, R.; Dudea, S.; Prosch, H.; Cerezo, E.; Nuernberg, D.; Serra, A.L.; Sidhu, P.S.; Radzina, M.; et al. EFSUMB Statement on Medical Student Education in Ultrasound [long version]. Ultrasound Int. Open 2016, 2, E2-E7. [CrossRef]

59. Cantisani, V.; Dietrich, C.F.; Badea, R.; Dudea, S.; Prosch, H.; Cerezo, E.; Nuernberg, D.; Serra, A.L.; Sidhu, P.S.; Radzina, M.; et al. EFSUMB statement on medical student education in ultrasound [short version]. Ultraschall Med. 2016, 37, 100-102. [CrossRef] 
60. EFSUMB. Minimum Training Recommendations. 2018. Available online: $w w w . e f s u m b . o r g / b l o g / ? p=1687$ (accessed on 25 August 2019).

61. Dietrich, C.F.; Averkiou, M.; Nielsen, M.B.; Barr, R.G.; Burns, P.N.; Calliada, F.; Cantisani, V.; Choi, B.; Chammas, M.C.; Clevert, D.A.; et al. How to perform Contrast-Enhanced Ultrasound (CEUS). Ultrasound Int. Open 2018, 4, E2-E15. [CrossRef] 